\title{
Preparing a healthcare workforce for geriatrics care: an Interprofessional team based learning program
}

Shelley B. Bhattacharya ${ }^{1 *} \mathbb{D}$, Stephen Jernigan², Myra Hyatt ${ }^{3}$, Dory Sabata², Shane Johnston ${ }^{1}$ and Crystal Burkhardt ${ }^{4}$

\begin{abstract}
Background: Improving the care of older adults in our healthcare system involves teams working together. As the geriatrics population rises globally, health science learners need to be prepared to work collaboratively to recognize and treat common conditions in geriatrics. To enable workforce preparation, the Institute of Medicine and the National League for Nursing emphasize the need to implement interprofessional active learning activities for undergraduate healthcare learners at academic medical centers.

Methods: The Geriatrics Champions Program was a team-based learning activity created to meet this task. It was a 24-month program, repeated twice, that impacted 768 learners and 151 faculty from medicine, occupational therapy, physical therapy, nursing, social welfare, psychology, pharmacy and dietetics. Each class was intentionally divided into 20 interprofessional teams that met four times annually. Each session focused on one geriatrics domain. The objectives were centered around the specific geriatrics competencies for each health profession, divided into the eight domains written in the "American Geriatrics Society IM-FM Residency Competencies". Evaluation consisted of individual and team Readiness Assessment Tests (RAT and tRAT). Surveys were also used to collect feedback using a Likert scale. Wilcoxon signed rank tests were used to compare iRAT and tRAT scores. Other analyses identified characteristics associated with tRAT performance group (Unpaired t-tests) and tRAT performance on the raw scale (Pearson correlation). Paired t-tests using a 7-level Likert Scale measured pre-post change in learner knowledge.

Results: Student tRAT scores were 30\% higher than iRAT scores $(p<0.001)$. Teams were more likely to score $100 \%$ on the initial tRAT attempt if more team members attended the current session $(p<0.001)$, more health professions were represented by team members in attendance $(p=0.053)$, and the team had a better track record of past attendance $(p<0.01)$. In the post-program evaluation, learners felt this program was helpful for their career preparation in interprofessional geriatrics care.
\end{abstract}

Conclusions: Learners understood that teams performed better than individuals in the care of older adults. Feedback from the learners and faculty was consistently positive and learners felt better prepared for geriatrics care. The program's benefits may extend beyond individual sessions.

Keywords: Workforce preparation, Geriatrics care, Healthcare systems, Interprofessional education, Team based learning

\footnotetext{
* Correspondence: sbhattacharya@kumc.edu

'University of Kansas Medical Center, School of Medicine, 3599 Rainbow

Blvd, Kansas City, Missouri 66160, USA

Full list of author information is available at the end of the article
}

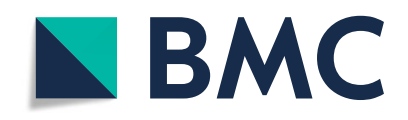

(c) The Author(s). 2021 Open Access This article is licensed under a Creative Commons Attribution 4.0 International License, which permits use, sharing, adaptation, distribution and reproduction in any medium or format, as long as you give appropriate credit to the original author(s) and the source, provide a link to the Creative Commons licence, and indicate if changes were made. The images or other third party material in this article are included in the article's Creative Commons licence, unless indicated otherwise in a credit line to the material. If material is not included in the article's Creative Commons licence and your intended use is not permitted by statutory regulation or exceeds the permitted use, you will need to obtain permission directly from the copyright holder. To view a copy of this licence, visit http://creativecommons.org/licenses/by/4.0/. The Creative Commons Public Domain Dedication waiver (http://creativecommons.org/publicdomain/zero/1.0/) applies to the data made available in this article, unless otherwise stated in a credit line to the data. 


\section{Background}

Preparing the workforce to work collaboratively in the care of older adults is an essential component to our healthcare system. Teaching geriatrics competencies to health profession learners is a necessary, but challenging, task. There is both a limited amount of time dedicated to teaching geriatrics and a limited proportion of clinician educators proficient in teaching geriatrics care. In geriatrics, interprofessional education (IPE) models have been used internationally for geriatric syndromes. Dementia care management, teaching the " 5 M" Framework outlined by the American Geriatrics Society, palliative care, falls risk assessments, and many other geriatric syndromes have been presented using an IPE model [1-4]. Most were performed during the clinical training years to students and faculty, after the didactic years, or as a one-workshop session. This program intervention adds to the current literature by providing a platform for a two-year didactic curriculum to provide continuous exposure to geriatrics care for interprofessional learners at the graduate-school level.

As our population matures, it becomes increasingly important for learners to recognize geriatrics syndromes, understand who their team players are and treat accordingly with optimal outcomes. The Institute of Medicine's 2003 report and the National League for Nursing's 2015 report emphasized a need to implement interprofessional active learning activities for undergraduate healthcare learners at academic medical centers $[5,6]$. The Geriatrics Champions Program was designed to create an inclusive interprofessional education (IPE) activity to introduce geriatrics competencies to six professions at an academic medical center with the goal of geriatrics care workforce preparation. The team-based learning (TBL) format was the foundation for promoting learner accountability, stimulating group interaction, and logistically managing large groups of learners. The five-year program impacted 768 learners and 151 faculty (Table 1) from medicine, occupational therapy, physical therapy, social welfare, psychology, nursing, pharmacy and dietetics (Table 2). Priorities for the program were to provide an active learning modality for learner engagement in geriatrics, a chance to practice team collaboration to mimic the workforce and an opportunity for learner and faculty scholarship. Post-program evaluation written comments were reviewed but no formal qualitative analysis was completed.

\section{Methods}

Aim

The Geriatrics Champions Program (GCP) was a fiveyear program from 2011 to 2016. The aim of the program was to create an active-learning platform to train interprofessional learners synchronously for geriatrics care in the workforce. It was funded by a Geriatric Academic Career Award by the Health Resources Services Administration (HRSA-10-228, Grant \#K01HP20492, PI: Dr. Shelley Bhattacharya).

\section{Content}

The GCP was a five-year grant; the first year was program and curriculum building followed by a 24-month curriculum, which repeated twice. Individual programs determined whether the course was required or elective. Each program was represented by a core group of one to two faculty. Faculty were chosen based on interest in IPE and prior collaborations with the team. The core faculty group of 6-10 met monthly to ensure the curriculum met their learners' needs, to be the content expert of relevant topics and to ensure the content met current healthcare guidelines. Core faculty also helped recruit the cadre of over 100 faculty to be team facilitators each year. Faculty were assigned a small student group to work with through the year.They were instructed to not lead the group, but guide the group if astray, allow for equal participation and spark discussion during lull moments. Faculty participated in required faculty development sessions annually to review the format, goals and responsibilities of each session. The lead facilitator was the Principal Investigator of the grant. She has been the lead facilitator for the six-profession interprofessional geriatrics clinic and brought her IPE

Table 1 Learner and Faculty Participation by Program Year

\section{Program Year Number of Learners Number of Faculty}

\begin{tabular}{lll}
\hline 1 & 134 & 16 \\
2 & 147 & 30 \\
3 & 150 & 33 \\
4 & 195 & 36 \\
5 & 142 & 36 \\
\hline
\end{tabular}


Table 2 Descriptive Statistics of Learners

\begin{tabular}{|c|c|c|c|c|}
\hline Variable & $\mathrm{N}=1,592$ & Mean & SD & Example Interpretation \\
\hline \multicolumn{5}{|l|}{ Participant Education Level } \\
\hline Student & $1,464(92 \%)$ & & & \multirow{2}{*}{$\begin{array}{l}92 \% \text { of learners were students; } 8 \% \text { were } \\
\text { graduates }\end{array}$} \\
\hline Graduates & $127(8 \%)$ & & & \\
\hline \multicolumn{5}{|l|}{ Learner Participation by Health Profession } \\
\hline Dietetics & $5(0.3 \%)$ & & & \multirow{8}{*}{$\begin{array}{l}\text { A total of eight health professions were } \\
\text { represented by the } 1,592 \text { program participants, } \\
\text { ranging from } 5 \text { participants }(0.3 \%) \text { in dietetics } \\
\text { to } 513(32 \%) \text { in Nursing }\end{array}$} \\
\hline Family Medicine - Resident & $127(8 \%)$ & & & \\
\hline Nursing & $513(32 \%)$ & & & \\
\hline Occupational Therapy & $299(19 \%)$ & & & \\
\hline Pharmacy & $280(18 \%)$ & & & \\
\hline Psychology & $21(1 \%)$ & & & \\
\hline Physical Therapy & $299(19 \%)$ & & & \\
\hline Social Work & $48(3 \%)$ & & & \\
\hline \multicolumn{5}{|l|}{ iRAT Performance of Teammates } \\
\hline At least 1 teammate with a perfect iRAT & $414(26 \%)$ & & & \multirow{2}{*}{$\begin{array}{l}26 \% \text { of Learners belonged to team where at } \\
\text { least one other team member scored } 100 \% \text { on } \\
\text { the iRAT }\end{array}$} \\
\hline No teammates with a perfect iRAT & $1,178(74 \%)$ & & & \\
\hline \multicolumn{5}{|l|}{ tRat Performance of Learners } \\
\hline Belonged to a team with a perfect tRAT & $764(48 \%)$ & & & \multirow{2}{*}{$\begin{array}{l}48 \% \text { of learners belonged to a team that } \\
\text { scored } 100 \% \text { on the initial tRAT attempt }\end{array}$} \\
\hline Did not belong to a team with a perfect tRAT & $827(52 \%)$ & & & \\
\hline \multicolumn{5}{|l|}{ Learner Effort on iRAT } \\
\hline Scored above the guess rate & $1,576(99 \%)$ & & & \multirow{2}{*}{$\begin{array}{l}\text { Learners scored above the guess rate on the } \\
\text { iRAT } 99 \% \text { of the time }\end{array}$} \\
\hline Scored at or below the guess rate & $16(1 \%)$ & & & \\
\hline Attendance Percentage & & $76 \%$ & $45 \%$ & $\begin{array}{l}\text { Learners attended } 72 \% \text { of the sessions, on } \\
\text { average }\end{array}$ \\
\hline iRAT Performance & & $67 \%$ & $19 \%$ & The average iRAT score for learners was $67 \%$ \\
\hline tRAT Performance & & $97 \%$ & $7 \%$ & The average tRAT score for learners was $97 \%$ \\
\hline
\end{tabular}

skills to this program. Faculty were given a certificate of appreciation each year.

The target audience was learners from Family Medicine residency programs; undergraduate medical clerkships in Family Medicine; Nurse Practitioner tracts for Adult Gerontology and Family Nurse Practitioner programs; Master's programs in Social Welfare, Occupational Therapy and Psychology; undergraduate Dietetics program; and doctorate programs in Physical Therapy and Pharmacy.

GCP content had thirty objectives divided into eight domains: Special Considerations in Geriatrics Care (Caregiver Burden, Medicare Basics, Function); Medication Management; Cognitive, Affective and Behavioral Health; Complex or Chronic Illnesses in Older Adults; Palliative and End of Life Care; Hospital Patient Safety, Transitions of care; and Ambulatory Care. The domains were guided by the American Geriatrics Society Internal Medicine-Family Medicine (IM-FM) Residency Competencies written in 2010, and expanded to fit each profession's geriatrics curricular competencies [3]. In addition to the IM-FM competencies, most professions had geriatrics competencies which were reviewed by core faculty and strategically matched to the appropriate domains to allow for all learners to achieve their respective competencies [8-12].
It was expected that program objectives would be better achieved through both dialog with students from other health professions and greater exposure to the GCP curriculum. Accordingly, as seen on Table 3, key variables of interest were the number of different health professions represented by team members in a given session-year and various measures of attendance.

The GCP format was a large classroom setting led by the lead facilitator. Learners were divided into 20 small groups of 6-8 learners and 1-2 faculty per group. Learners were intentionally divided into 20 interprofessional teams with at least three professions in each group. Four, 2.5-h sessions were held annually, each focused on one domain. Learners named their teams and stayed within their teams throughout the academic year. The members within each team changed each academic year due to graduation or course completion. Due to the size of the course, the online platform Blackboard ${ }^{\ominus}$ was used.

Finally, after each session, learners were given an evaluation consisting of ten Likert scale and open-ended questions of the value of the session, achieving the session's objectives, the perceived relevance of IPE to their education and the perceived benefits of IPE to their future practice. These evaluations were regularly reviewed, discussed by program designers to consolidate lessons 
Table 3 Descriptive Statistics by Team Performance Level

\begin{tabular}{|c|c|c|c|c|c|c|c|}
\hline \multirow[t]{2}{*}{ Variable } & \multicolumn{2}{|c|}{$\begin{array}{c}\text { Highest } \\
\text { Performing Teams }\end{array}$} & \multicolumn{2}{|c|}{$\begin{array}{c}\text { All } \\
\text { Other Teams }\end{array}$} & \multicolumn{2}{|c|}{ Difference } & \multirow[t]{2}{*}{ Example Interpretation } \\
\hline & Mean & $S D$ & Mean & $S D$ & $E S^{3}$ & $P^{4}$ & \\
\hline $\begin{array}{l}\text { Number of learners } \\
\text { assigned to team }\end{array}$ & 6.7 & 1.13 & 6.7 & 1.37 & 0.0 & 0.99 & $\begin{array}{l}\text { An average of } 6.7 \text { learners were } \\
\text { assigned to each team }\end{array}$ \\
\hline Team attendance & 5.08 & 1.60 & 4.16 & 1.69 & 0.56 & **** & $\begin{array}{l}\text { The highest performing teams had an } \\
\text { average of } 5.08 \text { learners in attendance }\end{array}$ \\
\hline $\begin{array}{l}\text { Team cumulative } \\
\text { attendance }\end{array}$ & 13.13 & 6.74 & 10.8 & 5.17 & 0.37 & $* *$ & $\begin{array}{l}\text { The highest performing teams had an } \\
\text { average cumulative attendance of } \\
13.13 \text { sessions }\end{array}$ \\
\hline $\begin{array}{l}\text { Team attendance } \\
\text { percentage }\end{array}$ & 0.77 & 0.23 & 0.63 & 0.24 & 0.60 & $* * *$ & $\begin{array}{l}\text { The highest performing teams had } \\
77 \% \text { of team members in attendance, } \\
\text { on average }\end{array}$ \\
\hline $\begin{array}{l}\text { Team cumulative } \\
\text { attendance percentage }\end{array}$ & 0.82 & 0.16 & 0.71 & 0.17 & 0.67 & $* * *$ & $\begin{array}{l}\text { The highest performing teams had an } \\
\text { average cumulative attendance of } \\
82 \%\end{array}$ \\
\hline $\begin{array}{l}\text { Number of health } \\
\text { professions in attendance } \\
\text { on a team }\end{array}$ & 3.96 & 1.02 & 3.68 & 0.99 & 0.28 & 0.053 & $\begin{array}{l}\text { The highest performing teams had an } \\
\text { average of } 3.96 \text { health professions } \\
\text { represented by team members in } \\
\text { attendance }\end{array}$ \\
\hline
\end{tabular}

${ }^{1} N=142$ teams with $100 \%$ on the initial tRAT attempt.

${ }^{2} N=75$ teams with less than $100 \%$ on the initial tRAT attempt.

${ }^{3}$ Cohen 's D Effect Size (ES) measure for difference between teams scoring 100\% (group 1) and less than 100\% (group 2) on the initial tRAT attempt.

$4 * p<0.05 ;{ }^{* *} p<0.01 ;{ }^{* *} p<0.001$.

learned but no formal qualitative analysis was completed.

\section{Logistics}

Learners were given 60 min of online pre-work before each session which included reviewing articles, online resources, and/or patient cases. Upon arrival to each session, learners were given an online individual Readiness Assessment Test (iRAT) valued at 10 points using the Blackboard $^{\circledR}$ platform. The iRAT consisted of ten multiple choice questions based on the prework material. Learners were shown only their total score, not which items they missed. Immediately following the iRAT (10 min), learners then completed a team Readiness Assessment Test (tRAT) using Immediate Feedback Assessment Technique (IFAT) scratch-off forms. The tRAT valued at 40 points, tasked each team with answering the same iRAT questions, but as a team. Each team member led the team to answer at least one question per session. Each faculty facilitator ensured that all professions' perspectives were shared for each question. The team IFAT forms had a designated key whereby a star was revealed once the correct answer was scratched off. These scratch-off forms allowed the teams to know if their team answer was correct by selecting the option revealing the star. If an answer was incorrect, they chose an alternate answer until the correct answer was selected. Four points were earned for the correct first attempt; two points if the correct answer was chosen on the second attempt, one point if the correct answer was chosen on the third attempt. The iRAT and tRAT scores were converted to percentages for consistency across scales and compared using Wilcoxon signed rank tests.

Since all students knew their iRAT score, but not which items they got wrong, they could use their team's reasoning to understand their errors. When all teams completed and submitted their IFAT forms (15 min), the course leader engaged all learners to review any questions as a large group that they found challenging. Teams voiced their support for or against an answer, which encouraged healthy discussion (15 min).

After a short break, the second half of the session consisted of an audio, video or live patient application case relevant to the session's objectives. Small groups were asked to rotate the roles of a team leader and team speaker to be used for the discussion. Five multiple choice questions were designed to encourage interprofessional collaborative discussion. After ten minutes of discussion, simultaneous reporting was used for each question with teams prepared to defend their answer when others refuted it. This activity allowed learners to apply their pre-work knowledge to the current case, explore their profession's role in the case, listen to how other professions could help with the patient's care, and ultimately gather the necessary information to explain their interprofessional care management choice. After the case discussion, five minutes were allocated for online feedback completion.

Points were awarded for each activity towards their team's final total score. Prizes were given at the end of the academic year to the team with the highest number of points. Participants who attended all four sessions 
Table 4 Learner Descriptive Statistics by Team Performance Level

\begin{tabular}{|c|c|c|c|c|c|}
\hline \multirow[t]{2}{*}{ Variable } & \multicolumn{2}{|c|}{$\begin{array}{c}\text { Highest Performing } \\
\text { Teams }^{1}\end{array}$} & \multicolumn{2}{|c|}{ All Other Teams ${ }^{2}$} & \multirow[t]{2}{*}{ Interpretation of the Mean } \\
\hline & Mean & $S D$ & Mean & $S D$ & \\
\hline Team tRAT score & 1.00 & 0 & 0.90 & 0.06 & $\begin{array}{l}\text { Learners that were not on the highest } \\
\text { performing teams had an average tRAT } \\
\text { score of } 90 \%\end{array}$ \\
\hline Learner iRAT score & 6.98 & 1.13 & 6.44 & 1.26 & $\begin{array}{l}\text { Learners on the highest performing } \\
\text { teams had an average iRAT score of } 6.98 \\
\text { out of } 10\end{array}$ \\
\hline $\begin{array}{l}\text { Range in iRAT scores } \\
\text { among team members }\end{array}$ & 3.66 & 1.67 & 3.33 & 1.8 & $\begin{array}{l}\text { The average range in iRAT scores among } \\
\text { learners on the highest performing teams } \\
\text { was } 3.66\end{array}$ \\
\hline $\begin{array}{l}\text { Maximum iRAT score on } \\
\text { a team }\end{array}$ & 8.71 & 1.35 & 8.05 & 1.31 & $\begin{array}{l}\text { The average maximum iRAT score } \\
\text { among learners on the highest } \\
\text { performing teams was } 8.71\end{array}$ \\
\hline $\begin{array}{l}\text { Minimum iRAT score on } \\
\text { a team }\end{array}$ & 5.05 & 1.43 & 4.72 & 1.78 & $\begin{array}{l}\text { The average minimum iRAT score } \\
\text { among learners on the highest } \\
\text { performing teams was } 5.05\end{array}$ \\
\hline $\begin{array}{l}\text { Teams with any members } \\
\text { with a perfect iRAT }\end{array}$ & 0.32 & 0.47 & 0.13 & 0.34 & $\begin{array}{l}\text { Highest performing teams included a } \\
\text { learner who scored } 100 \% \text { on the iRAT } \\
32 \% \text { of the time }\end{array}$ \\
\hline
\end{tabular}

${ }^{1} N=142$ teams with $100 \%$ on the initial tRAT attempt.

${ }^{2} N=75$ teams with less than $100 \%$ on the initial tRAT attempt.

and completed the program evaluation received a certificate of completion for their professional CV.

Materials required to run the program included the following:

1. Geriatrics Champions Program coursework: all prework, coursework, iRAT and case information is available electronically by contacting the corresponding author directly.

2. Interprofessional Faculty: Interprofessional leaders to meet monthly and discuss profession-specific curricula to be included within each of the eight domains. Although the interprofessional faculty together compiled the pre-work for each session, the profession who most closely matched the question's competencies led the session's pre-work development.

3. Certificates and Promotion letters: For learners and faculty partners.

4. Online platform: Blackboard ${ }^{\circledR}$.

5. IFAT forms: commercially available.

While TBL has been associated with better learning outcomes compared to other large group teaching methods, $[8,10]$ there remains a need to identify factors that make some teams more effective than others [13]. It was hypothesized that tRAT scores would be higher than iRAT scores and that tRAT scores would be higher on teams with more health professions in attendance and on teams with better attendance overall. It was expected that program objectives would be achieved through both dialog with students from other health professions and greater exposure to the GCP curriculum. Key variables of interest include the number of different health professions represented by team members and various measures of attendance (Table 3). Attendance refers to the number of team members present in a session. Attendance percentage refers to the number of team members present as a proportion of the total assigned to the team at the beginning of the year. Cumulative attendance reflects a team's track record of attendance. It represents the total sessions attended by all team members for all sessions within a year beginning with session one up to and including the current session. Similarly, cumulative attendance percentage represents cumulative attendance as a proportion of the total number of possible sessions attended by all team members.

\section{Data analysis}

The iRAT and tRAT scores were converted to percentages for consistency across scales. Because tRat scores, unlike those for the iRAT, demonstrated ceiling effects and were clustered near top of the score distribution, iRAT and tRAT scores were compared using Wilcoxon signed rank tests. Pearson correlation was used to identify characteristics associated with team performance on the raw tRAT scale. Unpaired t-tests were used to identify pre-post knowledge gains and differences between the highest performing teams and all other teams. The highest performing teams were defined as those scoring $100 \%$ on the initial tRAT attempt. This performance threshold served to classify teams by performance group 
while controlling for the number of tRAT attempts. All statistical analyses used two-tailed tests with $\mathrm{a}=0.05$ for a 95\% confidence level. In all cases, the session-year was the unit of analysis. Effect size interpretations, based on $r$ for Wilcoxon signed rank tests and Cohen's D for unpaired t-tests, reflect the guidelines from Cohen [18].

The analysis plan was adjusted post hoc to exclude both learners who did not make a good faith effort to complete the iRAT $(<1 \%$ of all learners) and teams containing another member scoring $100 \%$ on the iRAT (26\% of all learners, from Table 2). Students are assumed to make a good faith effort if they score above the guess rate, $25 \%$ for a multiple-choice exam with four response options per question. It's important to jointly account for individual and team performance, because participants on teams with another member that scores $100 \%$ on the iRAT may have an advantage on the tRAT. If a team member scores $100 \%$ on the iRAT and remembers how they responded with certainty, then one team member knows the tRAT answers in advance, potentially biasing the estimate of the difference between iRAT and tRAT scores. Table 4 shows comparisons between teams that got all questions correct on the tRAT first attempt and those that did not on the pooled sample of all teams across all sessions and years $(n=217)$. Tests were repeated on a restricted sample including only those teams with no members that scored $100 \%$ on the iRAT $(n=$
142). Results reported are from the restricted sample, though results are robust across both samples.

\section{Results}

Table 2 provides descriptive statistics of the GCP learners. Over the five years of the Geriatrics Champions Program, iRAT scores $(\bar{x}=67 \%)$ were lower than tRAT scores $(\bar{x}=97 \%)$ by $30 \%(p<0.01$, effect size $=0.85)$. Team performance on tRATs was correlated with cumulative team attendance percentage $(\mathrm{r}=0.20, p<0.05)$, team attendance percentage $(\mathrm{r}=0.19, \mathrm{p}<0.05)$, team attendance $(\mathrm{r}=0.20, \mathrm{p}<0.05)$, average iRAT score among all attending team members $(\mathrm{r}=0.23, p<0.01)$, and maximum individual iRAT score among team members $(\mathrm{r}=$ $0.23, \mathrm{p}<0.01)$. The significance of average and maximum iRAT scores among team members are consistent with recent research finding positive associations between team performance and higher performing individuals on the team $[5,13]$. All associations reported above can be considered small in magnitude according to common measures of effect size [7].

From Fig. 1, the highest performing teams had higher cumulative attendance percentages $(\mathrm{t}=4.18, p<0.01)$, higher cumulative attendance $(\mathrm{t}=2.78, p<0.05)$, higher attendance percentage $(\mathrm{t}=3.70, \mathrm{p}<0.01)$, and a higher attendance $(t=2.86, \mathrm{p}<0.01)$. From Table 3 , the highest performing teams also had an average of 3.96 different

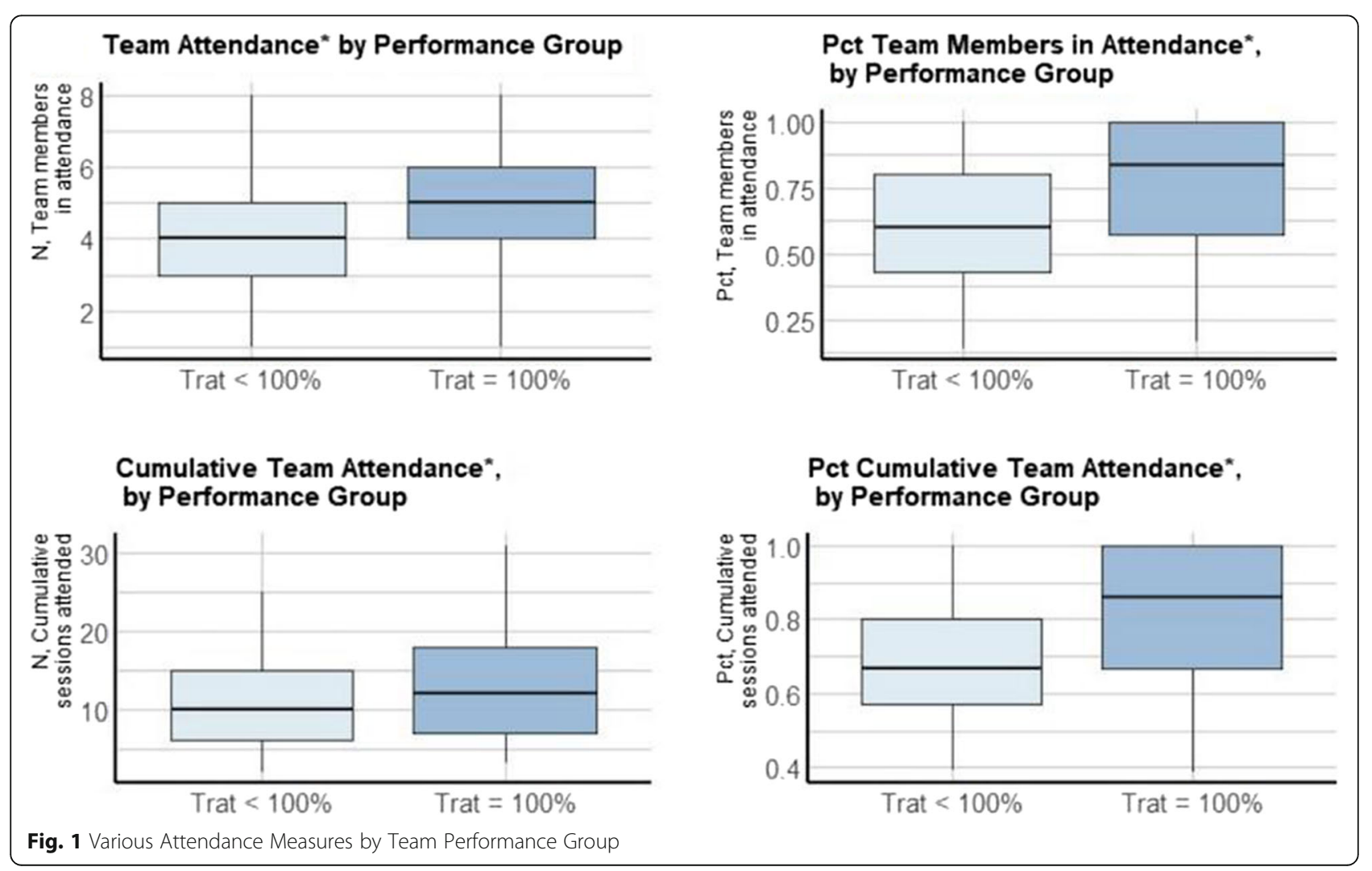


health professions represented compared to 3.68 on all other teams ( $p=0.053$, effect size $=0.28)$.

In the post-program evaluation, written comments (summarized in Table 5) generally indicated that learners felt this program was helpful for their career preparation. One learner wrote, "I really enjoyed participating in the program and hope that future psychology learners will become involved. I discussed this program with a number of faculty members at other institutions during my residency/internship interviews and they were all very impressed with the effort you and the other faculty members have made to help train learners in providing IP care. If I weren't leaving for my clinical residency/internship this summer I would sign up for

Table $\mathbf{5}$ Learner feedback (one as worst and five as best)

\begin{tabular}{ll}
\hline \multicolumn{1}{c}{ Question } & \multicolumn{1}{c}{ Response Tally } \\
\hline $\begin{array}{l}\text { On a scale from one to five, one being the worst } \\
\text { and five being the best, how beneficial were } \\
\text { these GCP sessions for your future practice? }\end{array}$ \\
\hline & $\begin{array}{l}\text { Learn how to work interprofessionally, aware of how } \\
\text { medications impact a person's functional daily life, prepared } \\
\text { us for IP communication and in team groups, understanding } \\
\text { insurance, developing comprehensive plan for geriatric } \\
\text { patients, use the websites mentioned, see how different } \\
\text { professions view different problems, speak to patients } \\
\text { directly about their conditions and medications, } \\
\text { understanding fall risks, know where to go to get answers, } \\
\text { always include the patient in the discussions. }\end{array}$ \\
practice? &
\end{tabular}

Fear of seeing Medicare patients with so many comorbidities and considerations, hard for Occupational Therapy to relate

Challenges to these sessions? sometimes, hard to get all professions to participate equally, wish they had more professions, had enough prior knowledge that they didn't find the content or IP time beneficial, overwhelmed.

Successful, everyone participated, good discussion, good skill building, team learning, raised collaborative approach Describe your IP experience today? to patient care, deepened trust amongst colleagues, eyeopening to see how other professions viewed the same problems, case study was fun, "amazed by sheer power of knowledge gained by working in teams".

Learning with learners from other health and social care professions is likely to facilitate subsequent working professional relationships.

Learning with learners from other healthcare professions was more beneficial to improving my teamwork skills than learning only with my Mean $=4.08$ peers.

Collaborative learning was a positive learning experience for all of the healthcare leamers.
Mean $=4.04$

Mean $=4.19$ social care professions is likely to help to overcome stereotypes that are held about the different professions. 
next year!" Learners identified improvements on all nine medical knowledge assessment items (Table 6) from pre to post GCP participation.

\section{Discussion}

The Geriatrics Champions Program (GCP) was created to unite learners and faculty from seven professions for a workforce preparation course in geriatrics care. It was an interactive IPE program introducing geriatrics domains in a TBL format. Based on the feedback, it was a well-received IPE program that impacted 768 learners and 151 faculty over a five-year period. It will be interesting to see how these interventions impact actual practice in geriatrics care.

A committed faculty contributed to the development and delivery of active learning methods in this geriatrics delivery course. TBL was an effective modality, allowing for efficient delivery of content to a large group annually. Feedback from the learners and faculty was consistently positive and resulted in multiple scholarly poster and podium presentations for learners and faculty.

Learners understood that teams performed better than individuals in geriatrics care. The mean scores for the individual (iRAT) and team (tRAT) assessments differed significantly for each session $(p<.001)$ of the Program over the five years. Five-year data demonstrated that scores increased approximately 9-12 points out of 40, or $30 \%$, from the individual to the team assessment. The likelihood of higher performance may have stemmed from interaction and understanding of other professions. The 30\% difference remains statistically significant with a large effect size even when the sample is limited to students who both make a good faith effort to complete the pre-work assignments and are not on a team with another participant that scored $100 \%$ on the iRAT [7]. Learner feedback on Table 5 and changes in pre-post knowledge on Table 6 demonstrate the value the learners placed on practicing teamwork in geriatrics when in practice. The findings are consistent with previous research that finds individuals perform better in teams than they do alone [13-15].

Higher levels of participation in the GCP are associated with better team performance as measured by tRAT scores. The fact that percentage of team members in attendance is associated with tRAT scores suggest that raw attendance may provide an incomplete understanding of the relationship between attendance and team performance.

Prior work by Michaelson and Burlingame suggests that as much as $20-25 \mathrm{~h}$ of participation or participation in more than 12 sessions is needed for individuals to fully realize the benefits of learning in groups [19-20]. This study suggests that at least some benefits of the TBL method may be achieved with lower levels of participation. Importantly, both a team's in-session attendance and track record of past attendance is positively related to team performance. The significance of cumulative attendance, in particular, speaks to the potential latency of the Program's effect on geriatrics competency attainment. It provides evidence that program benefits may extend beyond individual sessions and last up to at least one year - the duration over which cumulative attendance was measured and over which teams remained unchanged.

Because attendance is largely voluntary, attendance measures allow for variation in team size across sessions. Swanson finds that small groups (defined as those less than five members) perform better in TBL settings [21].

Table 6 Learner pre-post content knowledge assessment

\begin{tabular}{|c|c|c|}
\hline $\begin{array}{l}\text { Using a scale of 1-7, please answer the following } \\
\text { questions by checking the box that most accurately } \\
\text { reflects your knowledge of the content area below: } \\
\text { "I was able to... }\end{array}$ & $\begin{array}{c}\text { Mean rating, } \\
\text { Before } \\
\text { participating }\end{array}$ & $\begin{array}{c}\text { Mean rating, } \\
\text { After } \\
\text { participating }\end{array}$ \\
\hline ...understand Medicare." & 3.24 & $5.23^{*}$ \\
\hline ...assess elder abuse." & 4.01 & $5.24 *$ \\
\hline ...assess function in older adults." & 4.64 & $5.65 *$ \\
\hline ...conduct a medication review & 3.89 & $4.87 *$ \\
\hline ...know which medicines to avoid in older adults." & 3.34 & $4.69 *$ \\
\hline ...share tools for medication adherence with my patients." & 3.75 & $5.15^{*}$ \\
\hline ...know how to assess depression in older adults." & 3.99 & $5.77 *$ \\
\hline ...recognize the components of delirium." & 4.10 & $5.78 *$ \\
\hline $\begin{array}{l}\text {...know what to do when I saw someone with dementia, } \\
\text { delirium or depression." }\end{array}$ & 3.87 & $5.55^{*}$ \\
\hline
\end{tabular}

*Significant difference, $p<0.05$

Key:: 1 = strongly disagree; 2 = moderately disagree; $3=$ slightly disagree; $4=$ neutral; $5=$ slightly agree; $6=$ moderately agree; $7=$ strongly agree 
However, this study is consistent with Thompson et al. in finding a positive association between team size and team performance on tRATs [22]. Skilled faculty facilitators may play an important role in supporting the effectiveness of teams with more members, offsetting "social loafing" or "too much talent" type effects [23-24]. Future TBL research would benefit by clearly describing the preparation, skill level and use of faculty facilitators. More research is needed about the role of these facilitators in possibly moderating the effects of team size on learning outcomes. Further TBL studies are needed to confirm effects on learning outcomes [16-17, 25]. TBL requires a paradigm shift in teaching that departs from traditional lecture models. It allows learners to actively acquire new knowledge, and enables the instructor to engage a large classroom environment to help learners apply their newly acquired IPE knowledge to a case scenario.

Multiple lessons can be shared from this interprofessional geriatrics workforce preparation course:

1. Identify IPE gaps in the current healthcare system and ensure your program assists in narrowing or closing the gap. For example, interprofessional geriatric care was a common element missing in our curriculum amongst our four Schools. The GCP served to narrow the gap by providing a platform to teach geriatric interprofessional competencies to learners from all four Schools;

2. Decide which professions you want to include in your program based on availability and needs, and be open to growth as others are interested;

3. Develop a reliable cadre of faculty from each profession that share your vision. Allow their expertise to build your curriculum. Creating a welcoming environment where suggestions and constructive criticism are invited, is key to building lasting partnerships;

4. Meet with your team regularly to share ideas, new content, benefits and challenges;

5. Learn about the components of TBL and how you can incorporate the iRAT, tRAT and Interactive Activity into your IPE activity;

6. Pick a location amenable to small group TBL learning activity discussion;

7. Make the activity a win-win for all, including your learners and faculty. Be flexible in how each profession can be involved and let the faculty determine what fits with their learners and curricula, (e.g. required or optional, all sessions or some sessions);

8. Collaborate with interprofessional faculty when making cases to ensure learners can identify their professional contributions to the case and pose thought-provoking questions to mimic a realistic healthcare system case;

9. Foster a collaborative environment where scholarship is encouraged for learners and faculty;

10. Create a peer evaluation system;

11. Seek funding to support program development;

12. Provide incentives for the learners to participate;

13. Gain institutional support for long-term sustainability.

The GCP was a successful program that incorporated an active learning tool to allow our future interprofessional workforce to engage in geriatrics content they may not have received otherwise. With more programs like these, we can hope that evidence-based, interprofessional geriatrics care will be provided for our older adults. Necessary handouts and content can be obtained via the corresponding author.

\section{Conclusion}

The GCP was an effective program to introduce our budding workforce to the value of interprofessional collaboration in geriatric care. In addition, the TBL format helped identify the benefits of team function. The 30\% difference in iRAT - tRAT scores demonstrates to the learners, program leaders and the geriatrics community at large that team efforts consistently outperform individual efforts. Both current and past attendance are important to team performance, consistent with an IPE program where later sessions build upon and expand on content presented at earlier ones. We hope the GCP provides a model that can be replicated at other academic institutions to provide workforce training wellneeded to care for our ever-expanding geriatric population.

\section{Abbreviations}

IM-FM: Internal Medicine-Family Medicine; tRAT: Team Readiness Assessment Test; iRAT: Individual Readiness Assessment Test; IPE: Interprofessional Education; TBL: Team Based Learning; GCP: Geriatrics Champions Program; R1-R3: 1st to 3rd year Family Medicine Resident; MSW: Masters in Social Work; IFAT: Immediate Feedback Assessment Technique; CV: Curriculum Vitae

\section{Acknowledgements}

The authors wish to acknowledge the 768 interprofessional learners who participated in this five-year program. Without them, this wouldn't have been possible. Thank you.

\section{Authors' contributions}

SBB was the lead instructor for the course, the creator of the online portal, the IRAT and tRAT evaluation lead and the primary author of the paper. SJe was the core faculty for the Physical Therapy cohort, MH was the core faculty for the Social Welfare cohort, DS was the core faculty for the

Occupational Therapy cohort, SJo performed data analysis and interpretation and CB was the core faculty for the Pharmacy cohort. All authors read and approved the final manuscript.

Funding

Geriatrics Academic Career Award, HRSA-10-228.

Grant \#K01HP20492. 
PI: Dr. Shelley Bhattacharya, 2009-2014

Role of funder: The funder didn't have a role in the design, data collection, analysis, data interpretation or writing of the manuscript.

\section{Availability of data and materials}

Data supporting the results reported in the article can be found on the Principal Investigator's secure computer's repository. This data cannot be shared as it would compromise the privacy of the individuals involved. Conditions for access will be limited and only upon approval by the corresponding author. Publicly archived datasets were not used or generated

\section{Declarations}

Ethics approval and consent to participate

This study was approved by the University of Kansas Compliance and Ethics Committee during every step of the project. Reference numbers are 12853 and 1662. Informed consent from all participants was obtained verbally and approved by the ethics committee.

\section{Consent for publication}

Not applicable.

\section{Competing interests}

The authors declare that they have no competing interests.

\section{Author details}

'University of Kansas Medical Center, School of Medicine, 3599 Rainbow Blvd, Kansas City, Missouri 66160, USA. ${ }^{2}$ University of Kansas Medical Center, School of Health Professions, 3901 Rainbow Blvd, Kansas City, Missouri 66160 USA. ${ }^{3}$ University of Kansas Medical Center, School of Social Welfare, 3901 Rainbow Blvd, Kansas City, Missouri 66160, USA. ${ }^{4}$ University of Kansas, School of Pharmacy, 3901 Rainbow Blvd, Kansas City, Missouri 66160, USA.

Received: 20 April 2021 Accepted: 9 September 2021

Published online: 16 November 2021

\section{References}

1. Dreier-Wolfgramm A, Michalowsky B, Austrom MG, van der Marck MA, lliffe $S$, Alder $C$, et al. Dementia care management in primary care : Current collaborative care models and the case for interprofessional education. Z Gerontol Geriatr. 2017;50(S2):68-77. https://doi.org/10.1007/s00391-017-122 0-8. Epub 2017 Mar 31. PMID: 28364258

2. Schwartz AW, Hawley CE, Strong JV, Phillips SC, Amir O, Ludwin BM, et al. A Workshop for Interprofessional Trainees Using the Geriatrics 5Ms Framework. J Am Geriatr Soc. 2020;68(8):1857-63. https://doi.org/10.1111/ jgs.16574 Epub 2020 Jun 18. PMID: 32557568: PMCID: PMC8114091.

3. Brown DK, Fosnight S, Whitford M, Hazelett S, Mcquown C, Drost JC, et al. Interprofessional education model for geriatric falls risk assessment and prevention. BMJ Open Qual. 2018;7(4):e000417. https://doi.org/10.1136/ bmjoq-2018-000417 PMID: 30515469; PMCID: PMC6231104.

4. Fulton AT, Richman K, Azar M, Sanzen K, Devine J, Ferrone C, et al. A novel Interprofessional palliative care and geriatrics curriculum for nephrology teams. Am J Hosp Palliat Care. 2020 Nov;37(11):913-7. https://doi.org/10.11 77/1049909120915462 Epub 2020 Apr 1. PMID: 32233775.

5. Institute of Medicine. Health professions education: A bridge to quality. Washington, DC: The National Academies Press; 2003.

6. NLN Vision Series: Interprofessional Collaboration in Education and Practice. Internet: http://www.nIn.org/docs/default-source/default-document-library/ ipe-ipp-vision.pdf?sfvrsn=14. Accessed 19 Apr 2021

7. Williams B C, Warshaw G, Fabiny A R, Lundebjerg N, Sauvigne K Schwartzberg J G, Leipzig R M. Medicine in the 21st century: Recommended essential geriatrics competencies for Internal Medicine and Family Medicine residents. Journal of Graduate Medical Education. 2010;2(3): 373-83

8. Adult-Gerontology Acute Care Nurse Practitioner Competencies, AACN, February 2012.

9. Essential Competencies in the Care of Older Adults at the Completion of a Physical Therapist Postprofessional Program of Study. https://geriatricspt. org/essential-competencies/. Accessed 20 May 2021.
10. Geriatric Social Work Competency Scale II with Life-long Leadership Skills: Social Work Practice Behaviors in the Field of Aging. Council on Social Work Education, https://www.cswe.org/getattachment/Centers-Initiatives/CSWEGero-Ed-Center/Teaching-Tools/Gero-Competencies/GeriatricSocia IWorkCompetencyScalell-LifelongLeadershipSkills.pdf.aspx. Accessed 20 May 2021.

11. Competencies, Criteria, And Client Outcomes, American Occupational Therapy Assn., http://epadgec.jefferson.edu/pdfs/ot\%20competencies.pdf. Accessed 20 May 2021.

12. ASCP Geriatric Pharmacy Curriculum Guide https://cdn.ymaws.com/www.a scp.com/resource/resmgr/docs/geriatriccurriculum/new_curriculumguide_2 021_v4.pdf. Accessed 20 May 2021.

13. Chung, E.K., Rhee, J.A., Baik, Y.H., \& A, O.S. The effect of team- based learning in medical ethics education. Medical Teacher. 2009:31:1013-7.

14. Black, E. W., Blue, A. V., Davidson, R., \& McCormack, W. T. Using team-based learning in a large interprofessional health science education experience. Journal of Interprofessional Education \& Practice. 2016;5:19-22.

15. Wheeler, S., Valentino, A. S., Liston, B. W., Li, J., \& McAuley, J. W. A teambased learning approach to interprofessional education of medical and pharmacy students. Currents in Pharmacy Teaching and Learning. 2019; 11(11):1190-5.

16. Cohen, J. Statistical power analysis for the behavioral sciences. Abingdon. England: Routledge; 1988.

17. Liu, S.-N. C., \& Beaujean, A. A. The effectiveness of team-based learning on academic outcomes: A meta-analysis. Scholarship of Teaching and Learning in Psychology. 2017:3(1):1-14.

18. Sisk, R. J. Team-based learning: systematic research review. Journal of Nursing Education. 2011;50(12):665-9.

19. Michaelsen LK, Knight AB, Fink LD. Team-Based Learning: A Transformative Use of Small Groups in College Teaching. Sterling, VA: Stylus; 2004.

20. Burlingame GM, McClendon DT, Alonso J. Cohesion in group therapy. Psychotherapy. 2011:48 (1):34-42.

21. Swanson, E., McCulley, L. V., Osman, D. J., Scammacca Lewis, N., \& Solis, M. The effect of team-based learning on content knowledge: A meta-analysis. Active learning in higher education. 2019;20(1):39-50.

22. Thompson, B. M., Haidet, P., Borges, N. J., Carchedi, L. R., Roman, B. J., Townsend, M. H., Levine, R. E. Team cohesiveness, team size and team performance in team-based learning teams. Medical education. 2015;49(4): 379-85.

23. Jackson JM and Williams KD. Social loafing on difficult tasks: Working collectively can improve performance. Journal of Personality and Social Psychology. 1985:49(4):937

24. Corbridge SJ, Corbridge T, Tiffen J, Carlucci M. Implementing team-based learning in a nurse practitioner curriculum. Nurs Educ. 2013;38(5):202-205.

25. Parmalee, D.X., \& Hudes, P. Team-based learning: A relevant strategy in health professionals education. Medical Teacher. 2012;34:411-3

\section{Publisher's Note}

Springer Nature remains neutral with regard to jurisdictional claims in published maps and institutional affiliations.

Ready to submit your research? Choose BMC and benefit from:

- fast, convenient online submission

- thorough peer review by experienced researchers in your field

- rapid publication on acceptance

- support for research data, including large and complex data types

- gold Open Access which fosters wider collaboration and increased citations

- maximum visibility for your research: over $100 \mathrm{M}$ website views per year

At $\mathrm{BMC}$, research is always in progress.

Learn more biomedcentral.com/submissions 